\title{
Altitude is the Main Driver of Coffee Leaf Rust Epidemics: a Large-scale Survey in Ethiopia
}

\author{
Kifle Belachew ${ }^{\text {aץ*}, ~ G i r m a ~ A d u g n a ~ S e n b e t a ~}{ }^{a}$, Weyessa Garedew ${ }^{a}$, \\ Robert Weingart Barreto ${ }^{b}$ and Emerson Medeiros Del Ponte ${ }^{\text {b\& }}$ \\ ${ }^{1}$ Department of Horticulture and Plant Sciences, College of Agriculture and Veterinary Medicine, Jimma University, \\ Jimma, Ethiopia; ${ }^{2}$ Departamento de Fitopatologia, Universidade Federal de Viçosa, 36570-900, Viçosa MG Brazil \\ \& These authors contributed equally to this work \\ Correspondence: Kifle Belachew, kiflekef@gmail.com
}

Arabica coffee (Coffea arabica L.) is native from Africa and Ethiopia is often regarded as its birthplace. Previously of little concern to Ethiopian farmers, coffee leaf rust (CLR) caused by the fungus Hemileia vastatrix is an emergent disease globally. To update the status of CLR, a large survey was conducted in 405 coffee fields across nine production zones of Oromia and Southern Nations Nationalities and Peoples (SNNP) regions. The disease, evaluated one time during the month of the peak for CLR intensity for each region, was present in every single field; mean incidence and severity ranged from 5 to $86.7 \%$ (mean $=35.3 \%$ ) and 0.22 to 55.5 (mean $=9.09$ ), respectively. $\mathrm{A}$ complementary log-log model predicted mean field severity from mean field incidence. Altitude, a known surrogate for temperature, was the main driver of the epidemics. Incidence and severity were highest at the lowland fields, where poorly managed plantations of local varieties grown under open sun were also more dominant. CLR intensity decreased with the increase in altitude at the highlands where well-managed improved varieties grown under the shade in forest systems dominate the scenario. This survey contributes to increase awareness of a growing problem in Ethiopia, especially for coffee fields at the highlands should temperatures rise and farmers cut forest to grow plantations of susceptible cultivars. Improving genetic resistance and adoption of best management practices are urgent to prevent the rapid surge of new races and mitigate crop losses currently overlooked by coffee farmers at the lowlands.

Keywords: Arabica coffee, Hemileia vastatrix, disease survey, production system 


\section{Introduction}

Only two of more than a hundred species within Coffea genus (Rubiaceae) are commercially grown worldwide: Coffea arabica, commonly known as Arabica coffee, accounts for two-thirds of total production; and Coffea canephora, the robusta coffee type that accounts for the remaining production (WCR 2018). Native stands of Arabica coffee can still be found at the understory of Ethiopian forests, but commercially grown fields has expanded considerably throughout two regions: Oromia and South Nations and Nationalities Peoples Region (CSA 2018; USDA 2018). Ethiopia currently leads coffee production in Africa, ranking fifth worldwide after Brazil, Vietnam, Colombia and Indonesia; 7.5 million bags of premium quality coffee were harvested in 2017 cropping season in Ethiopia (ICO 2018).

Coffee is the major cash crop in the country, accounting for $34 \%$ of the total export and $39 \%$ of agricultural export earnings of the nation (USDA 2018). In fact, 4.7 million smallholder Ethiopian farmers are directly involved in coffee production and about 15 million Ethiopians depend directly or indirectly on the coffee sector for their livelihoods (USDA 2018). The average coffee yields are generally much lower (620 kg/ha) (CSA 2018) than Brazil $(1,440 \mathrm{~kg} / \mathrm{ha})$ and Vietnam $(2,400 \mathrm{~kg} / \mathrm{ha})$, the world-leading

producers (ICO 2018). While Brazil produces both Robusta and Arabica coffee and Vietnam produces only Robusta, Ethiopia produces only Arabica coffee (ICO 2018).

Coffee production in Ethiopia has been threatened by diseases and insect pests, which remain among the major production constraints. Among the diseases, the three most economically important are Coffee berry disease (CBD) caused by Colletotrichum kahawae, coffee wilt disease (CWD) caused by Gibberella xylarioides and coffee leaf rust (CLR) caused by Hemileia vastatrix, an emergent problem in Ethiopia (Jefuka et al. 2010; Belachew et al. 2015). Coffee leaf rust is the most important coffee disease globally 
(Zambolim 2016; Talhinhas et al. 2017). Estimates of global crop losses due to leaf rust were roughly estimated at \$1-2 billion annually (McCook, 2006). CLR-affected leaves show chlorotic spots formed preceding the differentiation of suprastomatal uredinia where the spores are produced and further taken by air currents. After several cycles (infection, colonization, sporulation, dispersal) seasonal CLR epidemics leads to defoliation and, in the most severe cases, death of branches or entire plants (Avelino et al. 2015; Zambolim 2016; Talhinhas et al. 2017).

CLR was first reported in Ethiopia in 1934 (Sylvain 1958), but it has never been a major problem in the country. The increasing importance of coffee for the Ethiopian economy was the main driver of the recent shifts from local to improved, high-yielding, cultivars together with other cropping practices that may promote and suppress epidemics (Avelino et al. 2006; Jefuka et al. 2010). In general, changes in site selection (lower vs. higher altitude), cropping practices, and seasonal weather have been associated with the emergence of CLR epidemics in Ethiopia (Garedew et al. 2019; Daba et al. 2018). This hypothesis is based on empirical observations at specific regions. In fact, systematically collected and analyzed data covering all main coffee production area is currently lacking. In the early reports, during the 1990s, the national mean incidence of CLR in Ethiopia was estimated in 36.3\% (Wondimu 1991). During the late 1990s, mean disease severity (percent leaf area affected) as high as 27\% was recorded in the Hararghe coffee-growing region (eastern Ethiopia) (Derso et al. 2000). A recent survey in Yayu forest coffee, southwestern Ethiopia, reported 31.1\% mean incidence (Jefuka et al. 2010).

The current national status of CLR epidemics is yet to be documented, especially the geographical and altitudinal variation in disease intensity. It is well known the major role that seasonal weather/environmental plays the risk of CLR epidemic, mainly temperature, rainfall and humidity, which affect pathogenic processes such as infection, 
colonization and sporulation (Daba et al. 2018). CLR emergence in Ethiopia has also been associated with changes in temperature and rainfall patterns (Davis et al. 2012; Garedwe et al. 2019). In Central America, prior to the recent epidemics in Guatemala in 2012, coffee rust epidemics were unlikely to develop at production sites above one thousand meters where cooler nights prevail (Avelino et al. 2015). In Rwanda, CLR severity was estimated to decrease $1.5 \%$ percent unit per each 100 unitary increase in altitude (from 1400 to $1800 \mathrm{~m}$ ) (Bigirimana et al. 2012). In experiments conducted in the Setema district of Jimma Zone, Ethiopia, CLR severity was highest (16.9\%) at the lowland and lowest (5.7\%) at the highlands irrespectively of the cultivar (Daba et al. 2018).

Besides the altitudinal variation, the increasing level of human intervention (management) has resulted in various cropping systems used by Ethiopian farmers, currently defined as forest, semi forest, garden and plantation (Davis et al. 2012; Jefuka et al. 2010; Alemayehu et al. 2008). The plantation type has expanded considerably in Ethiopia in the last few years and this is usually more affected by rust compared with forests (Jefuka, 2010). The intensification of management includes soil correction with fertilizers, and improved nutritional status of coffee plants is known to reduce disease risk by boosting canopy growth and host resistance (Avelino et al. 2006). In addition, pruning facilitates light penetration in the canopy that impairs urediniospore germination. On the other hand, shading alleviates leaf stress by reducing the leaf temperature (Avelino et al. 2006).

The interaction of factors that boost crop productivity but can also favor epidemics is quite complex and may vary from region to region or field to field. Whether the previous findings on risk factors driving CLR in Ethiopia can be extrapolated to other major coffee growing areas of the country is unknown given the considerable variation in site characteristics and technology adoption (Teferi and Belachew, 2018). In this study, 
we hypothesize that CLR is a widespread problem that varies in intensity according to site characteristics that include site or region specific factors such as elevation, production system and farm management practices. We tested the hypothesis by surveying several hundred fields across nine geographic zones of Ethiopia in a single season during the peak of CLR intensity of the epidemics. Descriptive and inferential statistics were used to document and model the effect o geography, field characteristics such as elevation and the associated farming practices on disease incidence and severity. The information shall be useful to set priorities for improving CLR management and mitigating crop losses by an emergent disease of coffee.

\section{Material and Methods}

\section{Geographical coverage and climate}

A large-scale survey was conducted to obtain field-specific data on CLR incidence and severity as well as the associated farming practices in Coffea arabica, the only species grown commercially in Ethiopia (Davis et al. 2012). The large majority of Ethiopia's coffee is produced at smallholder farms (<0.5 ha) (USDA 2018). The survey was conducted in the two major coffee producing regions of the South and Southwest Ethiopia where more than two-thirds of the country's coffee plants are grown: Southern Nations Nationalities and Peoples Region (SNNPR) and Oromia. In total, nine administrative zones (hereafter zones) representative of the major coffee areas were selected: four zones in Oromia (Jimma, Illuababor, West Wellega and Bale) and five zones in SNNPR (Kaffa, Sheka, Bench-maji, Sidama and Gedeo) (Figure 1).

The coffee-growing regions are located in more humid regions of the country. Mean annual rainfall ranged from 1,500 to 2,200mm per year over the 1988-2018 periods 
(NMA 2018). The rainfall pattern is nearly mono-modal, and typically experiences eight consecutive wet months (>100mm per month) from March to October, with the heaviest rains falling from May to September (>200mm per month). A short dry season occurs from November to February (NMA 2018). These rain patterns allows a single coffee crop harvest season that spans from October to December.

The mean annual temperature averages $20.1^{\circ} \mathrm{C}$ at the lowland areas and $17.5^{\circ} \mathrm{C}$ at the highlands of the coffee growing areas included in this study. Daily minimum (coolest month) and maximum (warmest month) are in the ranges of $7.2-10.1$ and $26.7-30.3{ }^{\circ} \mathrm{C}$, respectively, depending on the altitude (NMA 2018). To compare temperatures across different site elevations, we selected three locations representing different altitudes (Gera, Jimma and Tepi) and obtained monthly means of mean daily temperature, relative humidity and total rainfall in 2017, the year of the survey, as well as overall means for the 37 years (January 1981 to December 2018). These data were gathered from NASA/POWER (https://power.larc.nasa.gov/data-access-viewer/).

\section{Sampling procedures}

A scouting team of coffee researchers from Jimma University and Jimma Agricultural Research Center (JARC) visited the farms between September 2017 and February 2018. The farms were visited once in the season during the time CLR incidence is usually at peak in the target region (Derso et al. 2000). Within each of the nine zones, three districts were selected at random, totaling 27 districts (Figure 1). In each district, three peasant associations (kebeles) were selected at a 5-15 $\mathrm{km}$ distance from each other along accessible rural roads, and five coffee fields from each kebele were sampled, thus totaling 
15 coffee fields per district. In total, 405 coffee fields (9 zones x 3 districts x 3 kebeles x 5 fields) were inspected.

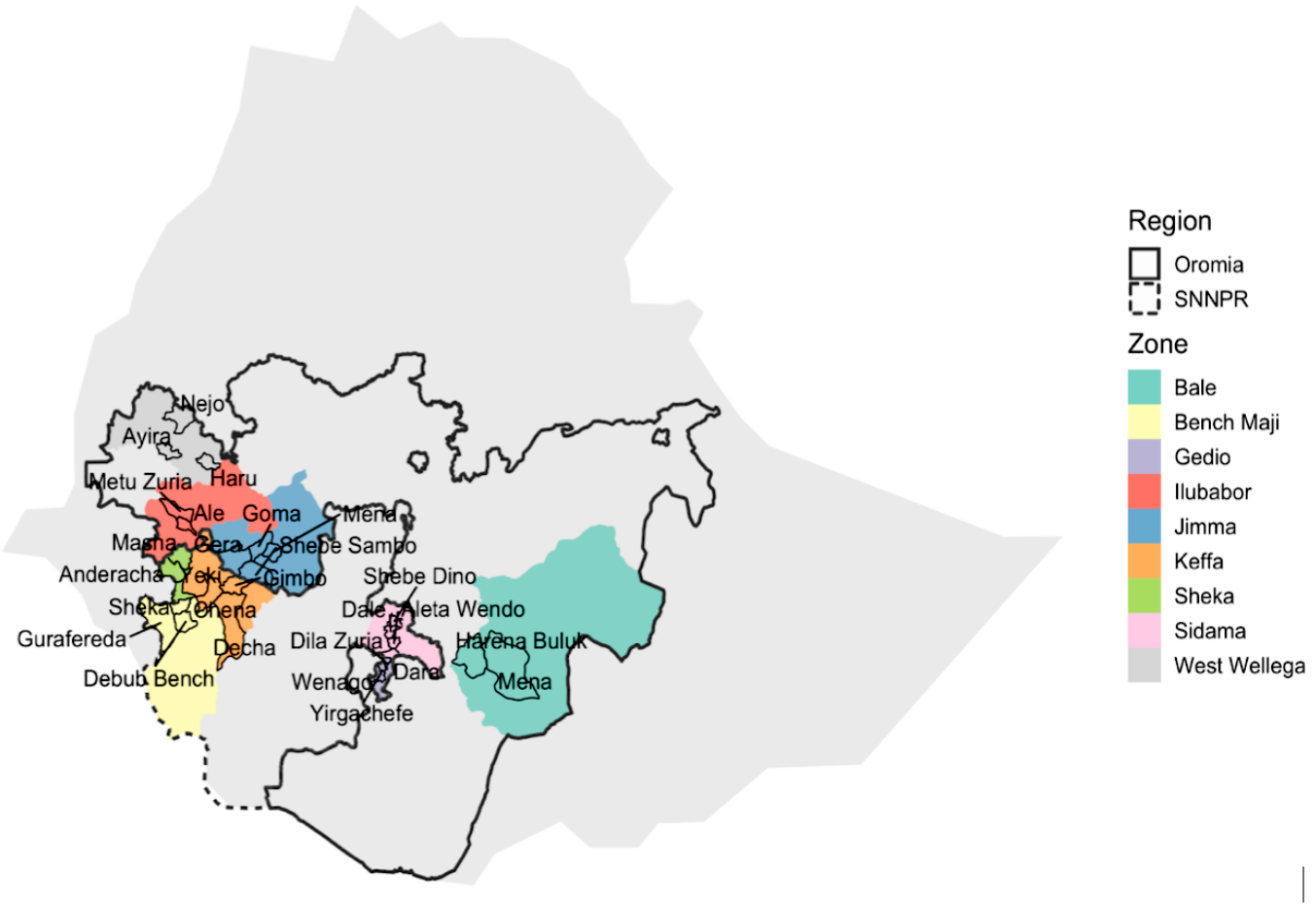

Figure 1 Ethiopia map depicting 27 districts (text labels) within which 15 coffee fields ( 3 peasant associations $x 5$ coffee farms) were selected and assessed for incidence and severity of coffee leaf rust survey program in 2017/18 growing season, totaling 405 fields. Three districts were selected within each of the nine Zones (colored legend) within two major Ethiopian Regions: Oromia (solid line) and Southern Nations, Nationalities, and Peoples' Region (SNNPR) (dashed line).

In each field, productive coffee trees were selected randomly in a zigzag fashion. Sample size was defined based on previous research that suggested a minimum of ten plants, each serving as source of data resulting from the examination of all leaves of six branches, to obtain estimates of disease intensity with sufficient precision (Kushalappa 1989; Jefuka et al. 2010). Therefore, a total of 10 to 30 trees were assessed per farm according to farm size and age uniformity. Exhausted, too old ( $>30$ years) or too young 
( $<$ five years) trees, as well as trees at the edge of the fields were not included in the sample.

\section{Field characteristics and farming practices}

The latitude, longitude and altitude data were recorded at each field. Five categorical (nominal or ordinal) variables were created to depict characteristics of the field as well as cultural practices: cropping system, cultivar, agronomic management and shade. The full description of the variables is presented in Table 1.

\section{Coffee leaf rust intensity data}

Leaves of six branches (one branch pair from the lower, middle and upper canopy) were randomly selected in a coffee plant. Percent leaf rust incidence at the branch level was obtained by counting healthy and symptomatic leaves (a single chlorotic or yellow spots on the lower leaf surface). Incidence at the tree level was obtained by averaging those values and field incidence was the average across trees. The conditional leaf rust severity (symptomatic leaves) was assessed visually and aided by a standard area diagram set (Kushalappa and Chaves, 1980) and recorded as percent area affected. The mean CLR severity (accounting for non-diseased leaves) for the field was the product of incidence and conditional (only diseased leaves) severity (Madden et al. 2007). 
Table 1 Categories, category level and description of site, crop and agronomic variables recorded at each of 405 coffee farms surveyed in Ethiopia in 2017 and 2018.

\begin{tabular}{|c|c|c|}
\hline $\begin{array}{l}\text { Categorical } \\
\text { factor }\end{array}$ & Level & Description \\
\hline \multirow{4}{*}{$\begin{array}{l}\text { Crop } \\
\text { Management }\end{array}$} & Unmanaged & Slashing or weeding once per year to facilitate harvesting \\
\hline & Minimal & Slashing or weeding, cultivation and use of organic fertilizers \\
\hline & Moderate & Periodic weeding, use of organic or inorganic fertilizer and pruning \\
\hline & Intensive & $\begin{array}{l}\text { Periodic weeding, use of organic or inorganic fertilizer, mulching, pruning, } \\
\text { stumping, canopy management and field sanitation }\end{array}$ \\
\hline \multirow[t]{4}{*}{ Cropping System } & Forest & $\begin{array}{l}\text { Wild stands of coffee, which exists naturally within the forest, and the farmer } \\
\text { undertakes minimal management and intervention. }\end{array}$ \\
\hline & Semi-forest & $\begin{array}{l}\text { Wild stands of coffee with increased farmers interventions than forest like } \\
\text { thinning of coffee trees, understory clearance and weed cutting, and planting of } \\
\text { naturally existing coffee seedlings within the canopy }\end{array}$ \\
\hline & Garden & $\begin{array}{l}\text { Coffee trees planted close to dwellings and range from a few plants up to a plot } \\
\text { of around } 1000 \text { plants. Garden coffees are usually part of a mixed cropping } \\
\text { system or agro-forestry and provide coffee for the household, local consumption } \\
\text { or the wider market }\end{array}$ \\
\hline & Plantation & $\begin{array}{l}\text { Commercial and intensively-managed coffee production system. Highly } \\
\text { productive and disease resistant coffee variety selection and use of } \\
\text { recommended practices are common. There is no definitive size limit for a } \\
\text { plantation but generally they are more than ten hectares. }\end{array}$ \\
\hline \multirow[t]{3}{*}{ Cultivar } & Improved & $\begin{array}{l}\text { Coffee varieties officially released by national coffee research system. Known v } \\
\text { registered by MoA. Mostly high yielder and disease resistant }\end{array}$ \\
\hline & Local & $\begin{array}{l}\text { Naturally existing indigenous coffee populations, highly adapted for the local } \\
\text { conditions. Well known by indigenous coffee farmers and passed from } \\
\text { grandparents. Mostly susceptible for major coffee diseases }\end{array}$ \\
\hline & Mixture & The mixture of improved and local coffee variety \\
\hline \multirow[t]{3}{*}{ Altitude } & High & $>1685$ meters above sea level \\
\hline & Mid & 1462 to 1685 meters above sea level \\
\hline & Low & $<14620$ meters above sea level \\
\hline \multirow[t]{3}{*}{ Shade Level } & Full shade & Estimated shade level greater than $60 \%$ \\
\hline & Mid shade & Estimated shade level between 30 and $60 \%$ \\
\hline & Sun & Estimated shade level is less than $30 \%$ \\
\hline
\end{tabular}

\section{Incidence and severity relationship}

The functional relationship between incidence and severity was studied to check whether severity could be predicted from incidence (Seem et al. 1984; Silva-Acuña et al. 
1999) and thus become useful to future surveys using a non-destructive, easier to obtain and more objective measure (Madden et al. 2007). We fitted a multilevel (linear mixed) complementary log-log model and hence the population-average intercept and slope could be estimated assuming a linear relationship (Paul et al. 2005; Spolti et al. 2015). Three models were tested (random intercepts and slopes; random intercepts alone; and random slopes alone) and the one yielding the lowest AIC was chosen. The predicted study-specific intercepts and slopes, known as best linear unbiased predictors (BLUPs), were estimated using maximum likelihood, together with the population-average parameters. The lmer function of the lme4 package of $\mathrm{R}$ was used for the mixed model analysis (Bates et al. 2015).

\section{Altitude and agronomic factors}

For modeling the effects of altitude and agronomic factors, a three-level (nested) random intercepts or a random intercepts and slopes model were fitted to severity data, which is a more informative variable than incidence (Bock et al. 2016). Using the multilevel model, we accounted for possible dependencies assuming that coffee fields within a same district are more similar to each other, rather than to fields from other districts. Fields were nested within districts, added as random effects in the model.

The model best fitting the data was selected based on the lowest Akaike Information Criterion (AIC). In addition, we tested whether the effect of altitude, as continuous variable, was dependent on any of the five categorical factors (zone, cropping system, cultivar, agronomic management and shade) based on the significance of the interaction term added (slope) to the three-level model. The lmer function of the lme4 package of $\mathrm{R}$ was used to fit the model with parameters estimated based on 
maximum likelihood. After model fitting and checking if the parametric test assumptions were met, incidence or severity were expressed in proportion and logit-transformed. Wald-type tests were performed to determine if the inclusion of the covariate in the model significantly affected the model coefficients at 5\% probability.

\section{Descriptive analysis of farming practices}

The levels of the four categorical variables that describe the farming practices were summarized as frequency, both overall and conditioned to geographic zone. A multiple correspondence analysis (MCA) was further used to map the associations between the categorical variables. A categorization of the altitude into three classes (split at tertiles) was used to aid visualization of its association with the other variables (Savary et al. 1995), but the effect altitude, as a continuous variable, was modeled using mixed model analysis (see modeling section).

\section{Data processing, availability, and reproducibility}

Exploratory analysis to prepare, transform, and visualize the data were performed using several R packages of the tidyverse (Wickham et al 2019). The fully annotated R scripts were prepared as R Markdown documents (Xie et al. 2018). All files (data, scripts, plots, etc) were organized as a research compendium (Gentleman and Temple Lang 2007) structured as an RStudio project (Gandrud 2016) and are freely available at https://osf.io/xejaz/ 


\section{Results}

\section{Incidence and severity of CLR}

Coffee leaf rust was present in every single visited coffee field. Average incidence at the farm level ranged from $9.5 \%$ to $86.7 \%$; mean and median values were $34.9 \%$ and $32.5 \%$, respectively, across the fields. Average severity on each farm ranged from $0.22 \%$ to 55.5\%; means and median values were 9.1 and 5.9\% respectively (Figure 2A). The multilevel model analysis showed no effect of zone on both the logit-transformed incidence $(P=0.0932)$ and logit-transformed severity $(P=0.163)$.

Because mean severity in a sample is the product of conditional severity (diseased leaves) and incidence (non-disease and diseased), an association between them was expected and it occurred in a non-linear fashion (Figure 2B). A random coefficients (lowest AIC, data not shown) complementary log-log (CLL) model best fitted their relationship $(\mathrm{F}=882.15, \mathrm{P}<0.001)$. Population average estimates of the unconditional (no covariates) model for the intercept and slope coefficients were $-5.363(\mathrm{SE}=0.25, \mathrm{t}$ $[$ Satterthwaite $]=-21.1)$ and $2.05(\mathrm{SE}=0.06, \mathrm{t}[$ Satterthwaite $]=30.2)$ respectively (Figure 2C).

\section{Altitudinal effects on CLR intensity by zone}

The amplitude of altitude across fields was relatively high $(\sim 1,000 \mathrm{~m})$, averaging 1,562 $\mathrm{m}$ $($ median $=1,632 \mathrm{~m}, \min 989$, and $\max =1,987 \mathrm{~m})$. Within each zone, the amplitude was generally greater 750m with two exceptions: Keffa and Bale (Figure 3A,B) . In general, the variation in disease intensity was larger within than between zones. There was a clear trend of decreasing incidence and severity with the increase in altitude, both 
overall and conditioned to the zones (Figure 3A,B). For all zones combined, incidence $\left(\chi^{2}\right.$ $=241, \mathrm{P}<0.001)$ and severity $\left(\chi^{2}=239, \mathrm{P}<0.001\right)$ decreased significantly with the increase in altitude. The population average estimates of the intercept and slope coefficients for the relationship between logit of incidence and altitude were 2.81 and -0.002 , respectively. The same coefficients were 2.33 and -0.0032 , for the relationship between logit incidence and altitude. P-values for the altitude vs zone interaction on incidence and severity were 0.018 and 0.039 , respectively. The zone-specific estimated trends (slopes) for those relationships ranged from -0.0007 to -0.0028 for incidence from -0.0005 to -0.0043 for severity across the zones (Fig 3C,D).
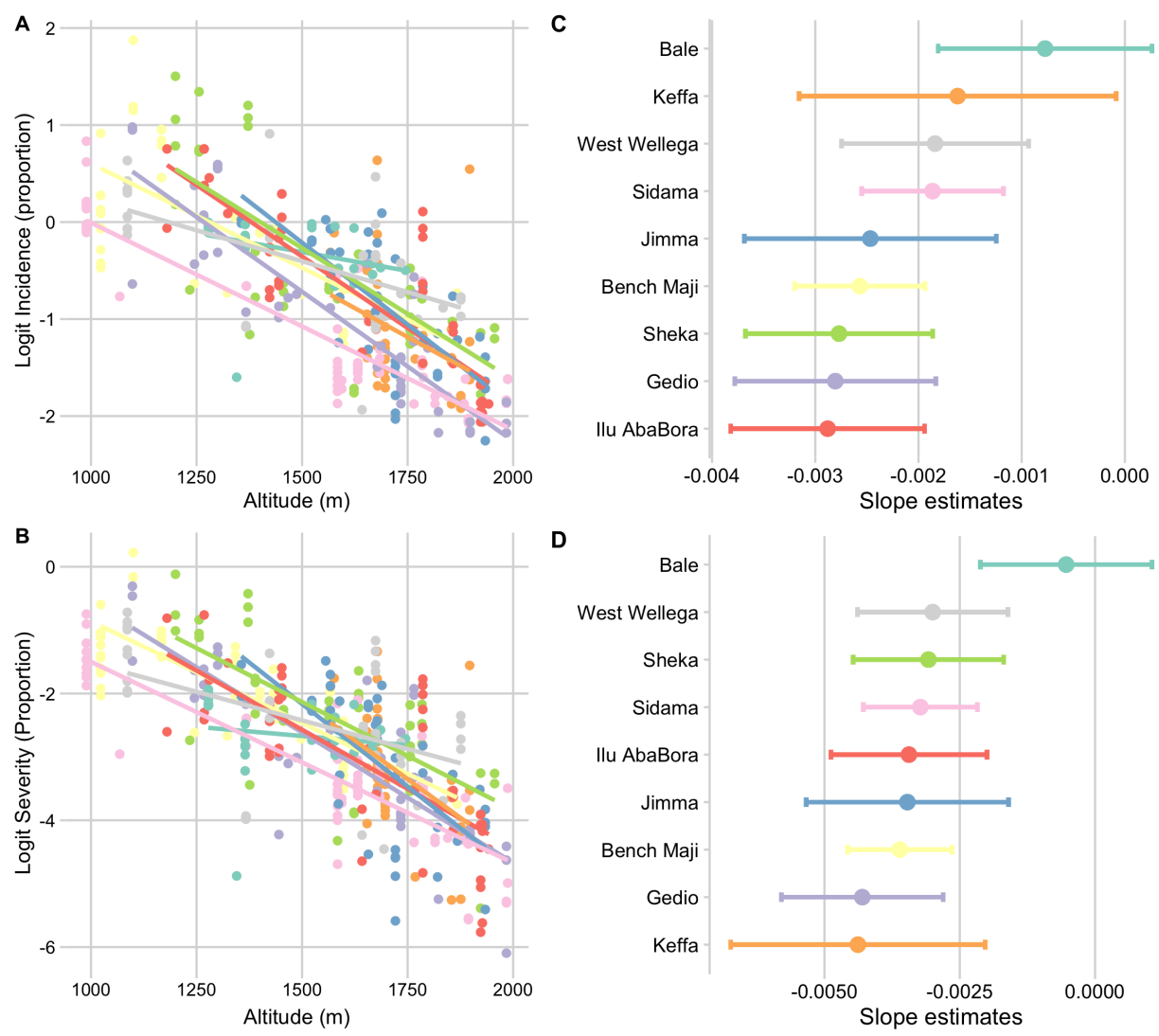

Figure 3 Relationship between the logit-transformed incidence (A) or logit-transformed severity (B) and altitude in 405 coffee fields surveyed at nine production zones of Ethiopia in 2017/18. The solid lines in A and $B$ represent the linear regression fit conditioned to geographic zone (colors). The slopes of the relationship between logit-transformed incidence and severity estimated from the fit of multilevel model are shown in $\mathrm{C}$ and $\mathrm{D}$, respectively. 


\section{Altitudinal effects on CLR intensity by agronomic factors}

Scatter plots depicting the relationship between severity and altitude (dots colored by levels of the categorical factors) suggested structuring of levels by altitude for all four factors (Figure 4A-D). Similar to when the effect of altitude was conditioned to zones, altitude strongly affected both responses, but in generally altitude effect was not dependent on the agronomic factors. The main effects of agronomic factor or altitude were highly significant in the full (up to the interaction) model $(P<0.001)$, but the interaction factor significantly affected CLR in two occasions for incidence and one for severity, out of four tested interactions for each response (Table 2). The fitted lines for the relationship between (logit-transformed) disease variable and altitude, for each level of factor, were mostly parallel (data not shown). The exceptions were cultivar and shade for incidence and cropping system for severity, but for which the P-values ranged from 0.022 to 0.046 , or slightly lower than the pre-defined alpha for statistical significance.

Table 2 Deviance (Type II Wald chisquare tests) for the interaction effect of altitude and agronomic factors (see levels in Table 1) on the means of logit-transformed incidence and logit-transformed severity of coffee leaf rust (CLR) epidemics observed in 405 fields located across nine geographic zones of Ethiopia during 2017/2018 season.

\begin{tabular}{|c|c|c|c|c|c|}
\hline \multirow[t]{2}{*}{ Interaction } & \multirow[t]{2}{*}{ DF } & \multicolumn{2}{|c|}{ CLR Incidence } & \multicolumn{2}{|c|}{ CLR Severity } \\
\hline & & $\chi^{2}$ & $P$-value & $\chi^{2}$ & $P$-value \\
\hline Altitude : Cropping system & 3 & 4.94 & 0.176 & 7.99 & 0.046 \\
\hline Altitude : Cultivar & 2 & 6.71 & 0.034 & 1.62 & 0.443 \\
\hline Altitude : Shade & 2 & 7.58 & 0.022 & 4.38 & 0.111 \\
\hline Altitude: Management type & 3 & 4.80 & 0.187 & 6.086 & 0.107 \\
\hline
\end{tabular}


The overall frequency of each the four cropping systems was similar in the country (20.2\% to $34.9 \%$ ) but there they were not evenly distributed across the zones. Forest was the most used system in Illubabor and Keffa, and not found in Bale, Bench Maji and Gedio zones. The plantation type was the most frequent in Bench Maji, Bale and West Wellega. The semi-forest system was found in all but the Sidama zone. Finally, the garden was the most frequent production system in Sidama and Gedio (Figure 4E).

Fields composed of mixtures of cultivars (improved and landraces) were dominant overall (50.8\%). The other half of the fields was planted solely with landraces (28.6\%) or improved cultivars (20.4\%). The relative proportions of each cultivar varied across the zones. The improved cultivars were found in all but Bale and Bench Maji zones. In Sidama, Gedio and Illubabor, more than $25 \%$ of the crops were planted solely with improved cultivars (Figure $4 \mathrm{~F}$ ). The sole use of landraces predominated in three (Bale, Bench Maji and West Wellega) out of the nine zones with frequency ranging from 40 to $60 \%$

The use of agronomic management practices was recorded in over $40 \%$ of the surveyed farms. However, one quarter of the fields were not managed at all. Intensively managed fields were found in all but Bale and Bench Maji zone; it was dominant in Gedio, Illubabor, Keffa and Sidama (Figure 4G). Jointly, 34\% of the farms were minimally or moderately managed. The cultivation under full shade dominated in around half of the farms (51\%), followed by mid-shade (19\%) and sun (28\%). It was largely dominant (> 70\%) in Keffa, Jimma and Sidama. Cultivation under open sun was mainly practiced in Bench Maji, Bale and West Wellega (Figure 4H). 
A

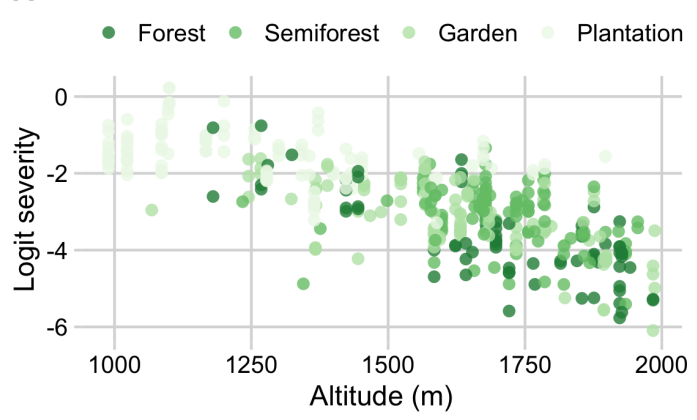

B

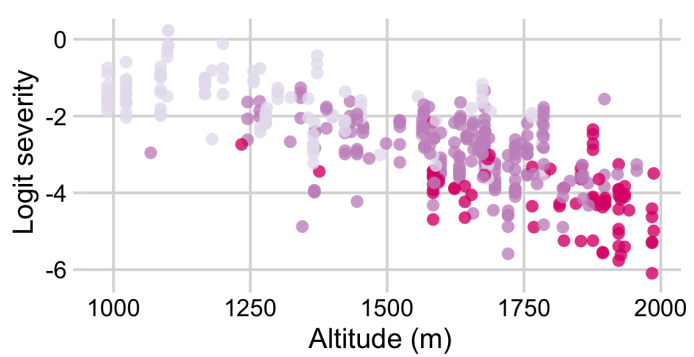

C Intensive - Moderate Minimal Unmanager

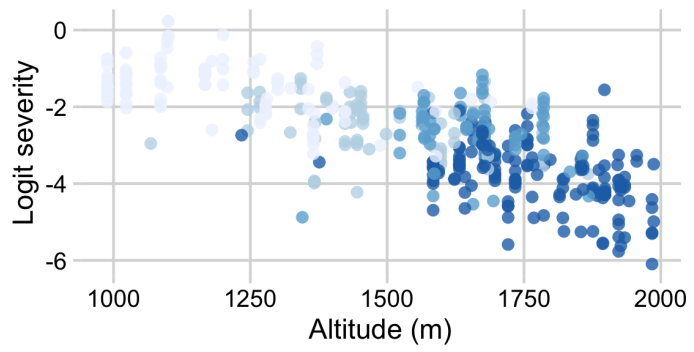

D

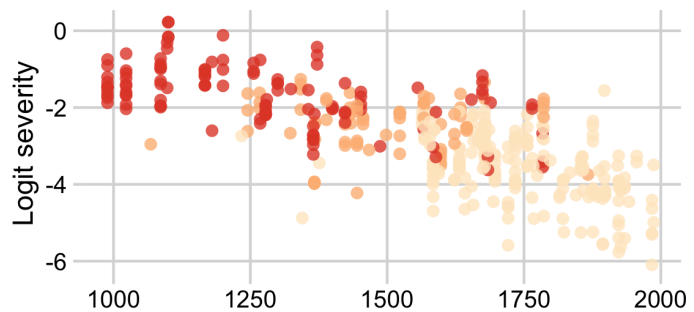

Altitude $(m)$
E

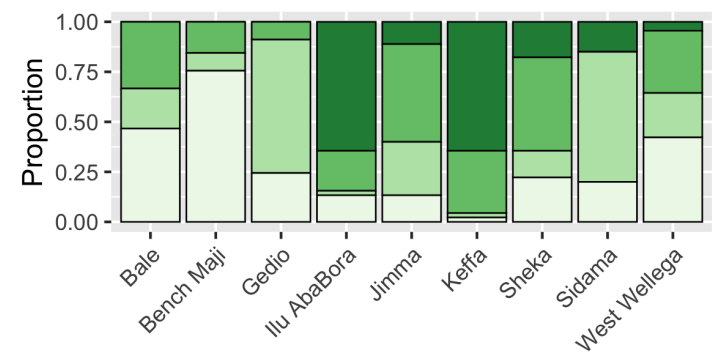

$\mathrm{F}$

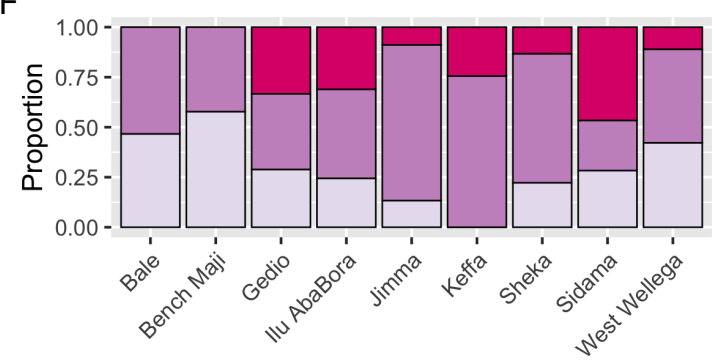

G

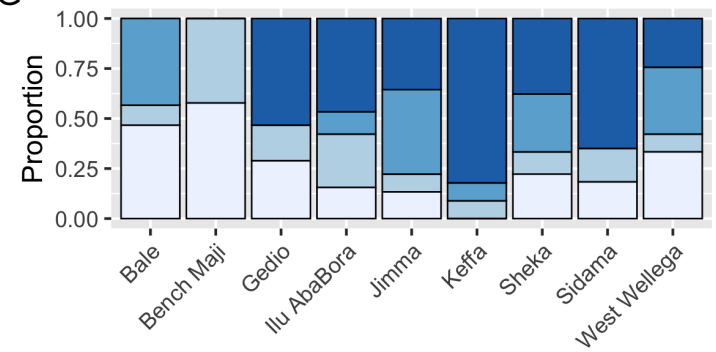

$\mathrm{H}$

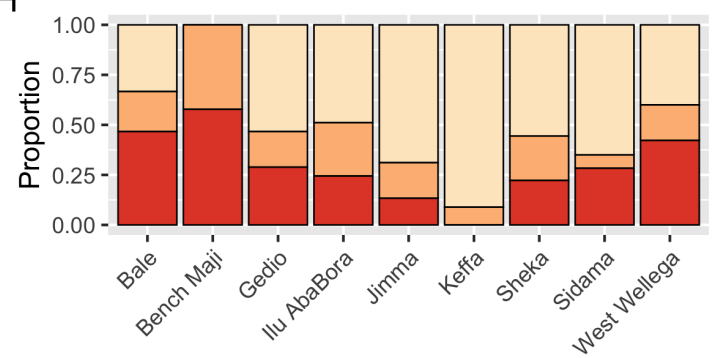

Figure 4 Relationship between logit-transformed coffee leaf rust severity and altitude in 405 Ethiopian coffee fields survey in 2017/18 growing season. Dots in plots A to D represent each field are colored by the levels of each of four categorical factors representing different agronomic factors: production system (A), cultivar (B), crop management level (C) and levels of shade (D). Plots $D$ to $G$ depict the relative proportion of coffee fields for the respective agronomic factor (gradient color). The number of fields per zone was 45 in most zones, with the exception of Sidama (60 fields) and Bale (30 fields). 


\section{Association among farming practices, zones and altitude}

The visual analysis of the MCA plot suggested clusters of fields that shared similar conditions of altitude and farming practices, thus confirming the univariate analyses. The first and two dimensions retained a modest proportion of $35.4 \%(22 \%+13.1 \%)$ of the total inertia (variation) contained in the data (Figure 5). The map shows a cluster of unmanaged plantations of landraces in open sun at altitudes lower than $1452 \mathrm{~m}$. Fields at Bench Maji, Bale, and West Wellega mostly represented these conditions (Figure 5). On the other hand, fields in Kaffa and Illubabor zones represented improved cultivars, forest systems and intensively managed farms under shade at altitudes greater than $1685 \mathrm{~m}$. An intermediate group of zones like Jimma, Sheka and Gedio, at moderate altitudes (1452 to $1685 \mathrm{~m}$ ) showed larger variation in the use of these practices (mid to upper left) (Figure $5)$.

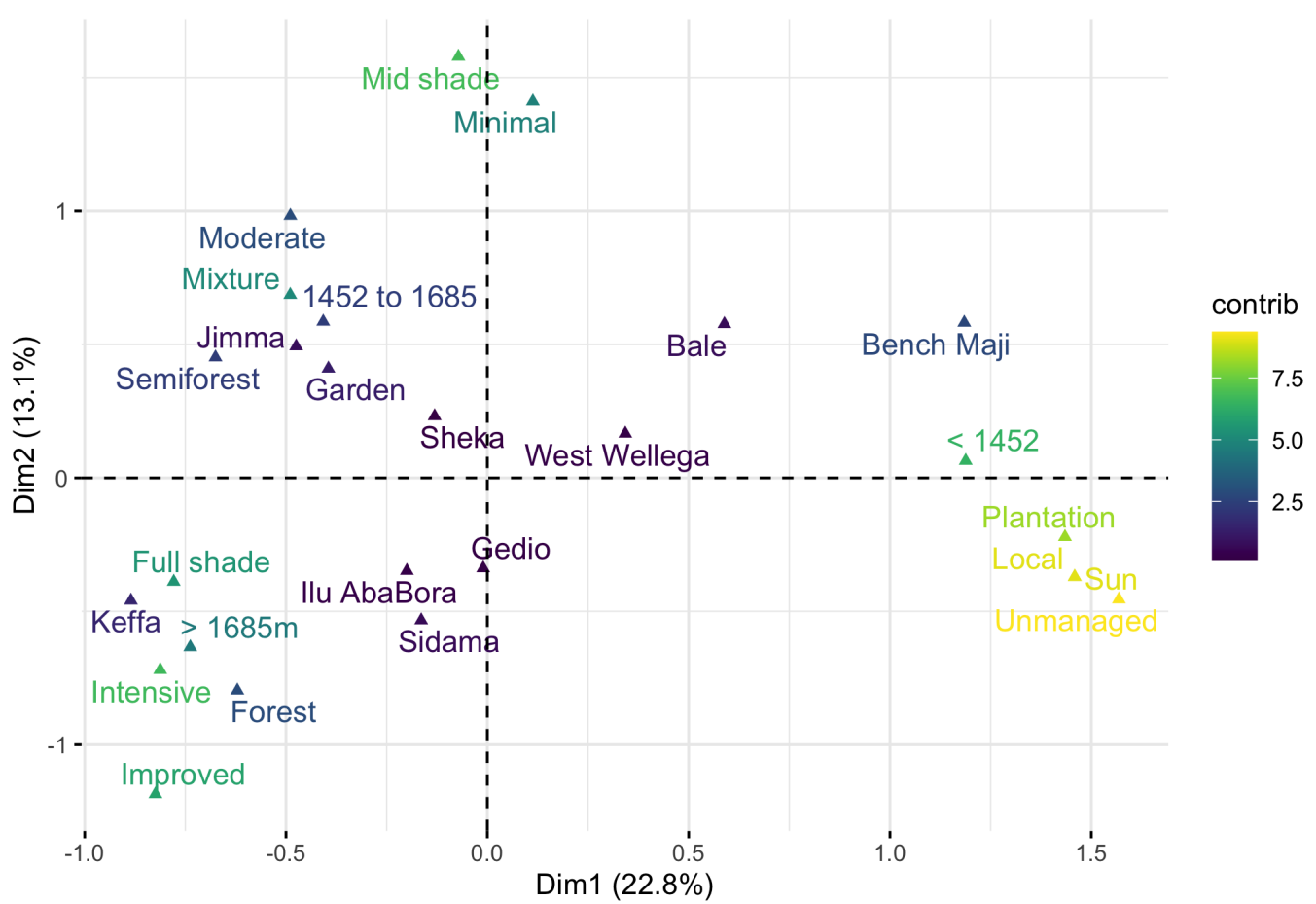

Figure 5 Multiple correspondence analysis plot for depicting the association among variables representing farming practices and site elevation (Table 1) as well as geographical zone (See Figure 1) for a sample of 405 Ethiopian coffee fields surveyed in $2017 / 18$ growing season. 


\section{Discussion}

In this study we gathered, to the best of our knowledge, the largest dataset from an extensive survey of CLR incidence and severity across hundreds of coffee fields located at nine major coffee-producing zones of Ethiopia. CLR was present in every single field, thus confirming its status of a widespread and emergent issue in the country. Levels of incidence and severity greater than $50 \%$ and $15 \%$, respectively, were found in one fourth of the fields, or around 100.

Previous surveys have highlighted the emergence of CLR at specific regions of Ethiopia (Derso et al. 2000). In the earliest surveys conducted during 1980s, overall means of CLR incidence was generally lower (13\%) than our country average estimated here (35\%) (Wondimu 1991). Since the 1990s, both the occurrence and the incidence of CLR have increased in some regions. An example is the Hararghe coffee-growing region where more susceptible varieties have been grown under open sun conditions (Wondimu 1991, Derso et al. 2000). A following survey conducted in Yayu forest coffee, southwestern Ethiopia, reported CLR incidence averaging 31.1\% (Jefuka et al. 2010).

Changes in crop management practices during the last three decades have been linked to the emergence of CLR in Ethiopia, including the widespread use of high yielding but CLR-susceptible varieties grown in poorly managed plantation systems largely adopted at the lowlands (Jefuka et al. 2010). Most notably, the effect of altitude which explained most of the variation in CLR intensity in our survey, was expected given its known effect on epidemic components such as infection efficiency and duration of the latency period (Bock 1962; Kushalappa 1989; Brown et al. 1995; Daba et al. 2018; Garedew et al. 2019). Several studies conducted elsewhere, including Ethiopia, have shown that CLR severity tends to decrease with the increase in altitude where the fields experience relatively lower night time temperatures (Wondimu 1991; Hindorf and 
Omondi 2011; Daba et al. 2018; Garedew et al. 2019). In Central America, prior to the epidemics recorded in Guatemala during the early 2010s, CLR was less likely to occur at production sites above $1,000 \mathrm{~m}$, where cooler night and daytime conditions decreases infection efficiency and extends the latency period (Avelino et al. 2015). Moreover, CLR is generally reduced in highly diversified cropping systems commonly found in upland coffee areas (Avelino et al. 2006; Cerda et al. 2016). Our data corroborate this statement but we also reported cases where higher/lower CLR intensity at higher/low elevation, which may be due to local biological and agronomic factors acting in combination, that are known to influence disease risk (Avelino et al. 2006).

The surveyed fields were grouped into specific profiles according to biotic, abiotic and management factors, also defined as production situations that have been shown to drive CLR epidemics (Avelino et al. 2004; Willocquet and Savary 2004). These profiles are shared among the zones, but at varying proportions, which partially explained the variation in disease severity between zones as well within the same zone. For example, the plantation system was more frequently found in two of the nine zones, Bench Maji and West Wellega, where CLR intensity was generally higher, but the more severely affected fields were also located at the lower altitude in those zones. The shift from forest to plantations was reported as one of the reasons for the emergence of CLR disease in Ethiopia. A previous study showed increased incidence (up to 4-fold) in plantation compared with forest system (Jefuka 2010). In fact, we found a generally lower severity in Keffa and Illubabor where the forest system is dominant.

Landraces are still largely used and preferred by some smallholder coffee growers given their adaptability and relatively good yields. However, these materials are highly susceptible to other fungal coffee diseases besides CLR, thus compromising overall plant health status, contrary to improved varieties that generally exhibit better 
resistance to the major fungal diseases (Belachew et al. 2015). We found that half of the fields were planted with mixtures of local with improved material, but the sole use of landraces prevailed in a few areas, especially where CLR was also highest. The use of susceptible landraces was linked to the buildup of virulent pathogen populations, which might explain why newly released high yielding and good quality selected Arabica coffee varieties in Ethiopia have succumbed quickly to CLR (Jefuka et al. 2010; Belachew et al. 2015).

We found that only $20 \%$ of the 83 fields grown with improved varieties showed severity $>3 \%$, but these fields were not only at lower risk site $(>1,500 \mathrm{~m})$ but also well managed under full shade in a forest or semi-forest system. In addition to the generally more conducive weather conditions for CLR epidemics in the lowland coffee regions, only six improved varieties have been released and are under use in the lowlands (Teferi and Belachew 2018). The widespread use of a limited number of resistant varieties increases the risk of emergence of more virulent coffee rust strains, so shifts to improved varieties exhibiting partial rather than complete (race-specific) resistance should be promoted (Zambolim et al. 2016; Talinhas et al. 2017).

In most of the highlands examined here, more intensive management practices have been adopted, which helps to improve nutritional status of the crop that is known to impair disease progress by inducing host resistance defenses (Avelino et al. 2006). A reduced foliage area in pruned trees allows faster drying in less dense canopies and light penetration that are detrimental to urediniospore germination and colonization of coffee tissues (Avelino et al. 2004). Finally, the effect of shading on CLR epidemics have been documented in previous studies and both negative and positive effects were suggested, likely due to highly complex interactions among crop, environment and pathogen biology factors (Ehrenbergerova et al. 2017, DaMatta 2004, Muller et al. 2004, 
Lopez-Bravo et al. 2012). In general, we found that severity was lower in fields under full shade, but other factors that reduce disease risk were also present. A recent study conducted in fields at specific districts of Ethiopia reported increased CLR epidemics due to more shading that lead to increased air humidity levels (Garedew et al. 2019). Regardless of the inconsistent effect of shading on CLR epidemics (Liebig et al. 2019), its use is broadly recognized as environmentally beneficial to coffee agro-ecosystems worldwide, including in Ethiopia (Workafes and Kassu 2000).

Regardless of the widespread prevalence of the disease in severe levels at some production situations that require attention, the impact of CLR in coffee yields of Ethiopia is not yet perceived as a problem as other diseases that directly affect yield, like coffee berry disease (Belachew et al. 2015). CLR is generally regarded as a minor disease of lowland coffee regions and hence, coffee breeding programs have given low priority for CLR-resistant varieties (Garedew et al. 2019). New races have overcome the resistance in a small set of varieties released for the lowlands.

Previously not common in the Ethiopian uplands (Garedew et al. 2019) CLR was found in every single upland field, but generally at lower severity than those at the lowlands. This is likely due to decreased daily mean temperatures in the high elevation sites. In fact, mean monthly temperatures at Gera and Jimma were around $3^{0} \mathrm{C}$ lower than in Tepi, the latter representative of the lowland area (Supplemental Figure 1). Given that our data were limited to one year, and that variation from year to year is expected (Wondimu 1991; Garedew et al 2019), it will be instructive to further monitoring CLR in the uplands in future seasons. The strong relationship that we found between incidence and severity, confirming previous studies in Brazil and Peru (Silva-Acuna et al. 1999; Otiniano et al. 2019), may be useful to obtain reasonably accurate estimates of severity 
from incidence data, a more objective and easy to obtain measure that will help to speed up data collection and optimize resource use in future surveys.

In conclusion, our results contribute to increase the awareness of a growing problem that can potentially threat areas that are still under lower risk. Should projected increases in temperatures associated with global change occur in Ethiopia (Davis et al. 2012) the situation might be similar to the emergence of CLR in the uplands Central America (Avelino et al. 2015), although the long-term climate change hypothesis has been rejected based on a recent modeling study in Colombia (Bebber et al. 2016). Similar modeling studies would be useful in Ethiopia should the parameters be adjusted to more diversified systems. Appropriate actions should be taken immediately to address the problem at the lowland areas, including breeding for resistantce and improving management practices to mitigate crop losses due to leaf rust, still largely overlooked. Otherwise, more drastic measures such as fungicide applications, not currently used in Ethiopia, may be required to control the disease as practiced in other countries (Zambolim 2016). The low yields at the lowland areas are already pushing coffee growers into opening new planting areas in the highlands (Davis et al. 2012), a shift that can be detrimental to a unique ecosystem that harbor the last pockets of native genetic diversity of C. arabica essential future prospects in coffee breeding.

\section{Acknowledgements}

This work represents part of a research project to be submitted to Jimma University College of Agriculture and Veterinary Medicine of Jimma University by Kifle Belachew as a requirement for him to be awarded a PhD in Horticulture. The authors would like to express their gratitude to Ethiopian Institute of Agricultural Research and Jimma 
University for Financial and logistics support to this research work. K.B. also thanks the World Coffee Research for providing funding for his split-PhD training period in the Departamento de Fitopatologia at the Universidade Federal de Viçosa (Brazil). Moreover, we want to thank the staffs of Jimma Agricultural Research Center Department of Plant Pathology Research, particularly Mr. MamoAbiye, Mr. NagasaDachasa, Mr. LegeseHagos for their unreserved support during the survey and data collection.

\section{Author's contribution}

KB, GA and WG conceived and designed the study. KB collected the data and wrote the manuscript. EMD performed the statistical analyses, interpreted the data and wrote the manuscript. RWB wrote the manuscript. All authors read the manuscript and gave final approval for publication.

\section{References}

Alemayehu T, Esayas K, Kassu K (2008) Coffee development and marketing improvement plan in Ethiopia. pp. 375-381. In: Girma, A., Bayetta, B., Tesfaye. S., Endale, T. and Taye, K. (eds.). Coffee diversity and knowledge, EIAR, Addis Ababa, Ethiopia.

Avelino J, Willocquet L, Savary S (2004) Effects of crop management patterns on coffee rust epidemics. Plant Pathology 53:541-7

Avelino J, Zelaya H, Merlo A, Pineda A, Ordon M, Savary S (2006) The intensity of a coffee rust epidemic is dependent on production situations. Ecological Modeling 197:431-447 
Avelino J, Cristancho M, Georgiou S, Imbach P, Aguilar L, Bornemann G, Läderach P, Anzueto F, Hruska AJ, Morales C (2015) The coffee rust crises in Colombia and Central America (2008-2013): impacts, plausible causes and proposed solutions. Food Security, 7:303-321

Bates D, Maechler M, Bolker B, Walker S (2015) Fitting Linear Mixed-Effects Models Using lme4. Journal of Statistical Software 67:1-48.

Bebber DP, Castillo AD, Gurr SJ (206) Modelling coffee leaf rust risk in Colombia with climate reanalysis data. Philosophical Transactions of the Royal Society B: Biological Sciences. 371(1709):20150458.

Belachew K, Teferi D, Gidisa G (2015) Screening of some Coffee arabica genotypes against coffee wilt diseases (Gibberella xylarioides Heim and Saccas) at Jimma, Southwest Ethiopia. International Journal of Sustainable Agricultural Research. 2: 66-76

Bigirimana J, Njoroge K, Gahakwa D, Phiri NA (2012) Incidence and severity of coffee leaf rust and other coffee pests and diseases in Rwanda. African Journal of Agricultural Research 7:3847-3852

Bock KR (1962) Seasonal periodicity of coffee leaf rust and factors affecting the severity of outbreak in Kenya Colony. Transaction of British Mycological Society 5:289-300

Brown JS, Kenny MK, Whan JH, Marrian PR (1995) The effect of temperature on the development of epidemics of coffee leaf rust in Papua New Guinea. Crop Protection $14: 671-676$

Bock CH, Chiang K, Del Ponte EM (2016). Accuracy of plant specimen disease severity estimates: concepts, history, methods, ramifications and challenges for the future. CAB Reviews. 11:1-21. 
Cerda R, Allinne C, Gary C, Philippe T, Harvey CA, Krolczyk L, Mathiot C, Clément E, Aubertot J-N, Avelino J (2016) Effects of shade, altitude and management on multiple ecosystem services in coffee agroecosystems. European Journal of Agronomy 82:308-319.

CSA (2018) Central statistics authority of Ethiopia, key findings of the 2017/2018 agricultural sample surveys, Available from: http://www.csa.gov.et/ Accessed on July 28, 2019

Daba G, Helsen K, Berecha G, Lievens B, Debela A, Honnay O (2018) Seasonal and altitudinal differences in coffee leaf rust epidemics on coffee berry disease-resistant varieties in Southwest Ethiopia. Tropical Plant Pathology 44: 244-250.

DaMatta FM (2004) Eco-physiological constraints on the production of shaded and unshaded coffee: a review. Field crops research 86: 99-114

Davis AP, Gole TW, Baena S, Moat J (2012) The impact of climate change on indigenous arabica coffee (Coffea arabica): predicting future trends and identifying priorities. PloS one $7: 47981$

Derso E, Gebrezgi T, Adugna G. (2000) Significance of minor coffee diseases of Coffea arabica L. in Ethiopia: a review. Proceedings of the workshop on control of coffee berry disease in Ethiopia; 13-15 August 1999. Ethiopia; Addis Ababa. 58-64

Ehrenbergerová L, Kučera A, Cienciala E, Trochta J, Volařík D (2017) Identifying key factors affecting coffee leaf rust incidence in agroforestry plantations in Peru. Agroforestry systems 92:1551-1565.

Gandrud C (2016) Reproducible Research with R and R studio. Boca Raton, FL: Chapman and Hall/CRC. 
Garedew W, Lamesa F, Fabrice P (2019) Landscape context and plot features influence the epidemics of coffee leaf rust (Hemileia vastatrix) in southwest Ethiopia. Archives of Phyto-pathology and Plant Protection 52: 71-89.

Gentleman R, Temple Lang D (2007) Statistical analyses and reproducible research. Journal of Computation and Graphical Statistics 16:1-23.

Hindorf H, Omondi CO (2011) A review of three major fungal diseases of Coffea arabica L. in the rainforests of Ethiopia and progress in breeding for resistance in Kenya. Journal of Advanced Research 2:109-120.

ICO (2018) International Coffee Organization annual report 2017/2018, World coffee production report, Available from: http://www.ico.org/Accessed on July 22, 2019 Jefuka C, Fininsa C, Adugna G, Hindorf H (2010) Coffee leaf rust epidemics (Hemileia vastatrix) in montane coffee (Coffea arabica L.) forests in southwestern Ethiopia. East African Journal of Science 4:86-95.

Kushalappa AC (1989) Coffee leaf rust biology and epidemiology. In: Kushalappa AC, Eskes AB. Coffee rust: epidemiology, resistance and management. Florida: CRC Press Inc pp:13-80.

Kushalappa AC, GM Chaves (1980) An analysis of development of coffee rust in the field. Fitopatologia Brasileira 5: 95-103.

Liebig T, Ribeyre F, Läderach P, Poehling HM, van Asten P, Avelino J (2019) Interactive effects of altitude, microclimate and shading system on coffee leaf rust. Journal of Plant Interactions 14: 407-415. 
Lopez-Bravo DF, Virginio-Filho Ede M, Avelino J (2012) Shade is conducive to coffee rust as compared to full sun exposure under standardized fruit load conditions. Crop Protection 38:21-29.

McCook S (2006) Global rust belt: Hemileia vastatrix and the ecological integration of world coffee production since 1850. Journal of Global History 1:177-195.

Madden LV, Hughes G, Van Den Bosch F (2007) The study of plant disease epidemics. St. Paul, NN:APS Press.

Muller RA, D Berry, J Avelino, D Biesse (2004) Coffee disease. In: J. Wintgens (ed). Coffee growing, processing, sustainable production: A guidebook for growers, processors and producers.

NMA (2018) National Meteorological Agency Climatological Services Team Annual Climate Bulletin, Addis Ababa, Ethiopia, Available from: http://www. ethiomet.gov.et/ Accessed on September 22, 2019

Otiniano AJ, Ventura RB, Huamán LA, Vera NJ, Cepero VC, Amez SB (2019) Relación entre la incidencia y la severidad de la roya del café (Hemileiavastatrix) en San Ramón, Chanchamayo, Perú. Journal of Science and Research: Revista Ciencia e Investigación $4: 1-9$.

Paul PA, El-Allaf SM, Lipps PE, Madden LV (2005) Relationships between incidence and severity of Fusarium head blight on winter wheat in Ohio. Phytopathology, 95:1049-60.

Savary S, Madden LV, Zadoks JC, Klein-Gebbinck HW (1995) Use of categorical information and correspondence analysis in plant disease epidemiology. Advances in Botanical Research 21: 213-240 
Seem RC (1984) Disease incidence and severity relationships. Annual Review of Phytopathology 22:133-50

Silva-Acuña R, Maffia LA, Zambolim L, Berger RD (1999) Incidence-severity relationships in the pathosystem Coffea arabica - Hemileia vastatrix. Plant disease, 83:186-188.

Spolti P, Shah DA, Fernandes JM, Bergstrom GC, Del Ponte EM (2015) Disease risk, spatial patterns, and incidence-severity relationships of Fusarium head blight in no-till spring wheat following maize or soybean. Plant Disease 99:1360-6.

Sylvain PG (1958) Some observations on Coffea arabica L. in Ethiopia, Turrialba, 5: 37-54

Talhinhas P, Batista D, Diniz I, Vieira A, Silva DN, Loureiro A, Tavares S, Pereira AP, Azinheira HG, Guerra-Guimarães L, Várzea V (2017)The coffee leaf rust pathogen Hemileia vastatrix one and a half centuries around the tropics. Molecular Plant Pathology 18:1039-1051.

Teferi D and Belachew K (2018) A review of coffee diseases research in Ethiopia. International Journal of Agriculture and Bioscience 7: 65-70

USDA (2018) United States Department of Agriculture, Ethiopian Coffee Annual Report. Foreign Agricultural Service, Global Agricultural Information Network, Available: http://www.fas.usda.gov/ Accessed on May 172019

WCR (2018) World Coffee Research Annual Report. Available at: https: //world coffeeresearch.org/ Accessed on August 25, 2019

Wickham H, Averick M, Bryan J, Chang W, McGowan LD, François R, Grolemund G, Hayes A, Henry L, Hester J, Kuhn M, Pedersen TL, Miller E, Bache SM, Müller K, Ooms J, Robinson D, Seidel DP, Spinu V, Takahashi K, Vaughan D, Wilke C, Woo K, Yutani H (2019) Welcome to the Tidyverse. Journal of Open Source Software 4:1686. 
Willocquet L, Savary S (2004) Effects of crop management pattern on coffee rust epidemics. Plant Pathology 53:541-547

Wondimu M (1991) Epidemiology and resistance of coffee leaf rust in Ethiopia. Ministry of Coffee and Tea Development. Addis Ababa, Ethiopia.

Workafes W, Kassu K (2000) Coffee production systems in Ethiopia. pp. 99-107.

Proceedings of the workshop on control of coffee berry disease in Ethiopia, 13-15 August 1999, Addis Ababa.

Xie Y, Allaire JJ, Grolemund G (2018) R Markdown: The Definitive Guide. Boca Raton, FL: Chapman and Hall/CRC.

Zambolim L (2016) Current status and management of coffee leaf rust in Brazil. Tropical Plant Pathology 41: 1-8. 

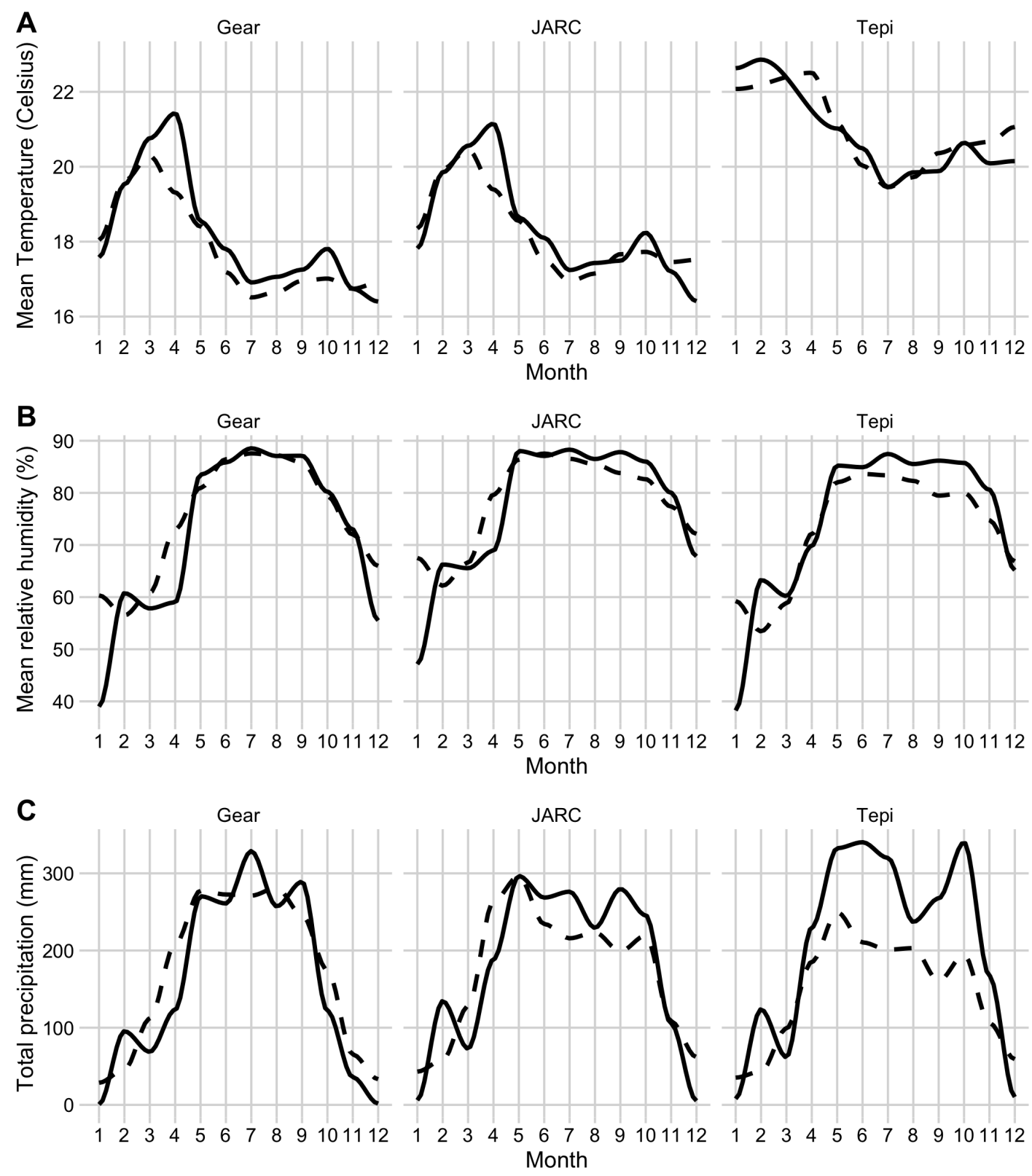

Supplemental Figure 1 Monthly summaries of mean daily temperature at 2-m (A), relative humidity at 2-m (B) and total precipitation ( $\mathrm{mm} /$ day) for three locations representing high elevation (Gera), mid elevation (Jimma) and low elevation (Tepi). Dashed line represents the overall means across years (1981 to 2018) and the solid line represents the data for 2018 year. Data provided by NASA POWER. 